\title{
Mapeamento e análise das áreas de preservação permanente e dos corredores de integração ecológica de Araraquara, SP
}

\author{
Mapping and analysis of permanent preservation areas \\ and green corridors in the city of Araraquara
}

\section{Ivan Damasco Menzori Luiz Antonio Nigro Falcoski}

\section{Resumo}

este estudo, é apresentada uma análise comparativa das diretrizes do Plano Diretor (PD) de Araraquara, de 2005, e de sua revogação seguida da revisão, em 2014, no que concerne às disposições espaciais das áreas de preservação permanente (APPs) e dos corredores de integração ecológica (Ciecos). Foram utilizados os dados da Secretaria Municipal do Meio Ambiente (SMMA), e da Secretaria de Planejamento Urbano (SPU), além de imagens de satélite do Google Earth, integrados ao software QGIS. Por conseguinte, foi possível determinar estatísticas de ocupação, assim como a classificação das APPs e dos Ciecos no perímetro urbano de Araraquara, SP. Constatou-se que a revogação com revisão do PD em 2014 possibilitou uma redução na largura dos Ciecos, de $70 \mathrm{~m}$ para $50 \mathrm{~m}$, e ampliou as finalidades de uso permitido. Com relação ao mapeamento, foi identificado que $81,6 \%$ das APPs e $59,6 \%$ dos Ciecos não apresentaram características de uso antrópico recente. A alteração proporcionada pela revogação com revisão do PD em 2014 descaracterizou as atribuições ambientais dos Ciecos, que possuíam uso permitido apenas para a implantação de parques lineares urbanos, o que poderia indicar uma realidade de desenvolvimento urbano que negligencia questões ambientais e desconsidera fatores inerentes à qualidade de vida dos cidadãos.

Palavras-chaves: Área de preservação permanente (APP). Corredor de integração ecológica (Cieco). Plano diretor de Araraquara.

\begin{abstract}
This paper presents a comparative analysis of the guidelines of the 2005 Master Plan of Araraquara city (PD) and its latest review, of 2014, regarding the space arrangement of permanent preservation areas (APPs) and green corridors (Ciecos). Data from the Municipal Department of the Environment (SMMA), and the Department of Urban Planning (SPU) were used, as well as satellite images from Google Earth, all integrated into QGIS software. It was possible to determine occupancy statistics, as well as the classification of APP's and Ciecos within the urban area of the city of Araraquara, Brazil. The researchers verified that the 2014 review of the PD implemented a reduction in the width of the Ciecos, from 70 meters to 50 meters, and expanded the purposes of allowed usage. In addition, 81.6\% of APP's and 59.6\% of the Ciecos did not present any characteristics of recent anthropic use. The changes introduced by the 2014 PD revision failed to consider the environmental attributions of the Ciecos, whose use had been allowed exclusively for the implementation of urban linear parks, which might indicate an urban development reality that overlooks environmental issues and ignores factors related to the quality of the life of citizens.
\end{abstract}

Keywords: Permanent preservation areas. Green corridor. Master plan of Araraquara.

Recebido em 20/10/15 Aceito em 08/05/16

Ivan Damasco Menzori
dade Federal de São Carlos São Carlos - SP - Brasil

Luiz Antonio Nigro Falcoski Universidade Federal de São Carlos São Carlos - SP - Brasil 


\section{Introdução}

O PD de Araraquara, criado com a Lei Complementar (LC) $\mathrm{n}^{\circ} 350$ de 27 de dezembro de 2005, revogado e revisado pela $\mathrm{LC}^{\circ} 850$ de 11 de fevereiro de 2014, apresentou princípios, objetivos, diretrizes e ações estratégicas para um crescimento mais ordenado da cidade, além dos mapas estratégicos (Mapes) de desenvolvimento social, econômico, urbano ambiental e institucional. É perceptível a substancial contribuição do SIG na elaboração dos mapas estratégicos, em que estes proporcionam uma representação dos planos de ação e das diretrizes por intermédio de desenhos temáticos e interpretativos (FALCOSKI, 2007). No caso do Plano Diretor de 2005, o Mapa Estratégico de Zoneamento Ambiental (Mape $\mathrm{n}^{\mathrm{o}}$ 4), de acordo com Falcoski (2007, p. 128), foi considerado como:

\section{[...] um processo complementar $e$ simultâneo ao Zoneamento Urbano tradicional, adotando-se o conceito já amplamente abordado da necessidade de um zoneamento urbano mais flexível de atividades urbanas não conflitivas, como resultado de pactos sociais, e mais rígido e restritivo no que concerne à função social da propriedade $e$ as salvaguardas ambientais, evitando-se o mecanismo do "rezoneamento urbano" tão ineficaz e socialmente injusto.}

O Mape $n^{\circ} 4$ apresenta, dentre várias outras informações, as disposições espaciais das faixas das APPs em todo o perímetro urbano, e define parâmetros claros a serem respeitados. Nenhum tipo de ocupação ou uso antrópico deveria ser permitido nessas estruturas tão importantes do zoneamento ambiental, pois elas contribuem diretamente na proteção dos cursos d'água e também na drenagem urbana, em que, nas ocorrências de enchentes, as várzeas acumulam o excesso de água a montante e liberam o escoamento de acordo com a capacidade do curso d'água. Além disso, essas faixas laterais permanecem secas durante a estiagem, quando as áreas permeáveis e a cobertura vegetal exercem forte influência na dinâmica do lençol freático, o que favorece recarga deste (SÁ, 2007).

A introdução dos Ciecos no PD de Araraquara, em complementação às APPs, foi uma importante iniciativa na preservação e proteção dos fundos de vale e das redes hídricas urbanas do município. Porém, somente a previsão dessas estruturas nas diretrizes do município não garante uma efetiva implementação física. O objetivo deste trabalho pode ser descrito como mapeamento e análise das disposições espaciais das APPs e dos Ciecos urbanos, de modo a viabilizar a determinação de estatísticas de ocupação dessas estruturas, assim como uma análise comparativa das diretrizes do PD de 2005 e sua última revogação com revisão do ano de 2014.

\section{Município de Araraquara, SP}

Conhecida como "Morada do Sol", Araraquara é uma cidade localizada na região central do Estado de São Paulo, a uma distância de $43 \mathrm{~km}$ do centro geográfico (Obelisco) do estado, e a $270 \mathrm{~km} \mathrm{da}$ capital. Ocupou a $14^{\mathrm{a}}$ posição no ranking do Índice de Desenvolvimento Humano Municipal (IDHM) do ano de 2010 (PROGRAMA..., 2010), e foi considerada a segunda melhor cidade do país segundo o Índice Firjan ${ }^{1}$ de Desenvolvimento Municipal (IFDM) do ano de 2009 (SISTEMA..., 2015). A cidade possui uma área de aproximadamente $1.003,6 \mathrm{~km}^{2}$ e altitude média de $664 \mathrm{~m}$ com relação ao nível médio dos mares, e sua população estimada no ano de 2015 era de 226.508 habitantes (IBGE, 2015).

\section{Tipos de cobertura vegetal de Araraquara}

De acordo com a tabela de quantificação da vegetação natural remanescente para os municípios do Estado de São Paulo do ano 2009, do Sistema de Informações Florestais do Estado de São Paulo (Sifesp), o município possuía cobertura vegetal predominante de floresta estacional semidecidual, com 4.166 ha, seguida de 2.036 ha de formações arbóreas/arbustivas em regiões de várzea e 2.311 ha de savana que, juntas, correspondiam a aproximadamente $8,5 \%$ da superfície do município (SISTEMA..., 2009).

\section{Redes hídricas de Araraquara}

A cidade de Araraquara possui redes hídricas extensas e diversificadas, que fragmentam e compõem o espaço urbano da cidade, como mostra a Figura 1. Com exceção do Córrego da Servidão, que se encontra canalizado em todo seu curso, e de esparsos trechos retificados em canais de concreto, no Ribeirão do Ouro e em alguns de seus afluentes, a hidrografia urbana do município permanece com sua configuração essencialmente incólume ao processo de urbanização. A importância de se conter o avanço da malha urbana sobre as APPs e, consequentemente, sobre os

${ }^{1}$ Um sistema da Federação das Indústrias do Rio de Janeiro (Firjan) que acompanha anualmente o desenvolvimento em educação, saúde, emprego e renda dos municípios brasileiros. 
recursos hídricos, foi efetivamente reconhecida no momento em que o PD de 2005 institucionalizou os Ciecos como elementos estruturadores do espaço urbano, que permitem ampliar a noção de áreas verdes com atribuições de recuperação e preservação dos fundos de vale.

$\mathrm{O}$ arranjo espacial das redes hídricas e suas APPs, aliado à distribuição dos Ciecos, favoreceram uma análise por meio da subdivisão da hidrografia urbana em trechos, sendo:

(a) o Ribeirão do Lageado, que corta o perímetro urbano em seu extremo oeste, com pequena extensão localizada em uma região composta, predominantemente, por chácaras de recreio;

(b) o Ribeirão das Cruzes e o Ribeirão do Ouro são os mais abrangentes da hidrografia urbana, estendendo-se por praticamente toda a malha urbana; e

(c) o Córrego do Capaúva e o Córrego da Água Azul desenvolvem-se dentro do perímetro urbano em extensões curtas, localizadas nos extremos sul e sudeste, onde prevalecem as atividades agrícolas de cultivo de cana-de-açúcar.

Assim sendo, os dados do estudo foram ordenados seguindo a fragmentação da hidrografia em cinco trechos principais:

(a) Ribeirão do Lageado;

(b) Ribeirão das Cruzes e afluentes;

(c) Ribeirão do Ouro e afluentes;

(d) Córrego do Capaúva; e

(e) Córrego da Água Azul.

As investigações de campo, necessárias para o desenvolvimento deste estudo, foram realizadas por amostragem não aleatória e seletiva ${ }^{2}$, que se mostrou apropriada para os objetivos alçados. A definição das unidades de amostra priorizou as estruturas de APP e Cieco classificadas como não vegetadas, acessíveis à visitação, em que possíveis usos ou ocupações do solo dessas estruturas não foram identificados ou não se mostraram bem definidos, conforme será explicitado sucessivamente. As localizações aproximadas das unidades de amostragem investigadas também estão dispostas na Figura 1.

\section{Corredores de integração ecológica}

Definidos no Sistema Nacional de Unidades de Conservação da Natureza (SNUC, Lei $n^{\circ}$ 9.985/2000) como porções de ecossistemas naturais ou seminaturais que interligam unidades de conservação, os corredores ecológicos são instrumentos de gestão e ordenamento territorial que possuem o objetivo de promover a preservação dos processos ecológicos, como a dispersão de espécies (animais e sementes, por exemplo), a recolonização de áreas degradadas, o aumento da cobertura vegetal e o favorecimento do fluxo gênico e da viabilidade de populações que demandam áreas maiores (além das unidades de conservação) para sobreviver (BRASIL, 2015).

$\mathrm{Na}$ última revogação com revisão do $\mathrm{PD}$ (PREFEITURA..., 2014a) de 11 de fevereiro de 2014, os Ciecos estão dispostos na página 67. Segundo uma porta-voz da Prefeitura Municipal de Araraquara, apontada como representante e responsável pela coordenação da Secretaria de Planejamento Urbano (SPU), a denominação Cieco, utilizada no PD do município, refere-se apenas a uma faixa adicional de transição entre a paisagem urbana e a APP, ou seja, a concepção mais abrangente da terminologia "corredor ecológico", apresentada no SNUC, não é totalmente compatível com a definição apresentada no PD de 2014 do município.

\section{Objeto do estudo e metodologia aplicada}

\section{Ciecos segundo o PD de Araraquara}

No PD de Araraquara, em sua última revogação com revisão de 2014, os Ciecos foram definidos como faixas adicionais de $50 \mathrm{~m}$ de largura, além das faixas de APP $(30 \mathrm{~m})$, ao longo de cada margem dos cursos d'água, fundos de vale ou talvegues do conjunto das redes hídricas que configuram o espaço urbano e municipal de Araraquara. Essas faixas destinam-se à transição entre a paisagem urbana e a APP, sendo o seu uso permitido para iniciativas de proteção do ambiente natural, mobiliário urbano, preservação dos mananciais, projetos paisagísticos, ciclovias, parques, equipamentos de lazer e recreação, entre outros.

\footnotetext{
${ }^{2} E$ É aquela em que a localização das unidades de amostra - no escritório, através de mapas, ou no campo - é estabelecida arbitrariamente. Esse critério arbitrário normalmente é baseado nas condições de acessibilidade ou na suposta acuidade do observador em perceber que determinados locais da área florestal são representativos da população sob estudo (MINISTÉRIO...; INSTITUTO..., 2012, p. 171).
} 
Figura 1 - Croqui da hidrografia urbana de Araraquara

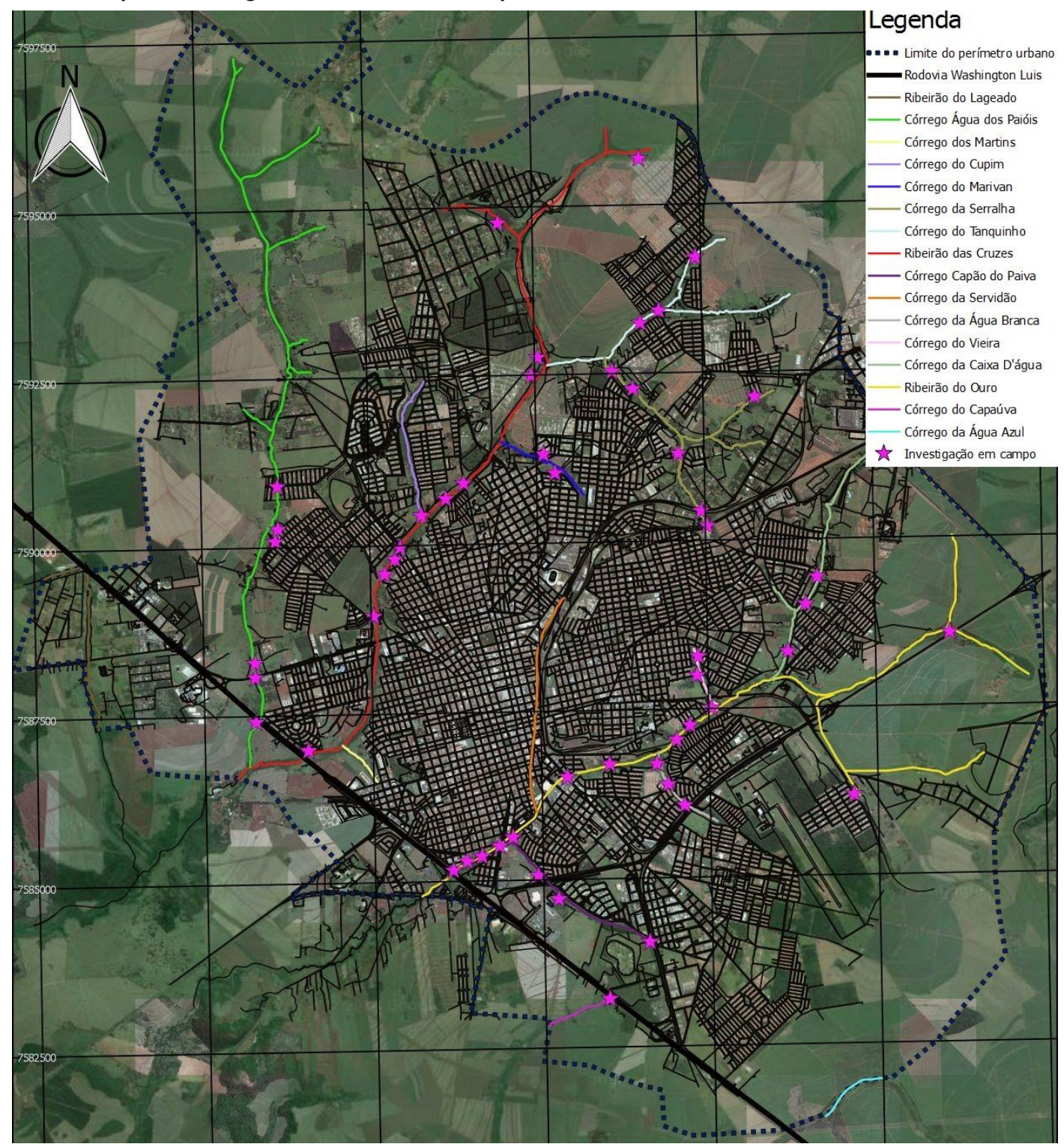

De acordo com a representante SPU de Araraquara, a terminologia Cieco, utilizada no PD de 2005, poderia ser considerada como inadequada, pois a principal finalidade dessas estruturas seria apenas a transição entre APP e paisagem urbana, com características parciais de unidade de conservação e uso permitido em casos específicos. A faixa com largura de $100 \mathrm{~m} \mathrm{(70} \mathrm{m}$ de Cieco mais $30 \mathrm{~m}$ de APP, de acordo com o PD de 2005) foi considerada excessiva pela SPU, sendo esta a única justificativa apresentada para a redução proporcionada pela revogação com revisão do PD em 2014. Argumentos como esses, confusos e inconsistentes, poderiam representar um desconhecimento das atribuições ambientais do Cieco e de toda a fundamentação que substanciou sua institucionalização no PD de 2005, ou até mesmo revelar uma visão antropocêntrica/ utilitarista do poder público municipal em relação ao meio ambiente, desvinculando-o do contexto mais abrangente de espaço urbano ambiental.

Nesse caso, entende-se que a "nova" definição com ampliação das finalidades antrópicas, utilizadas no PD de 2014, poderia ser compreendida como inadequada. Além de ampliar algumas ações antrópicas que podem descaracterizar a noção de parque linear urbano, inicialmente presente no PD de 2005, também, como já mencionado, a revisão do PD de 2014 reduziu a largura mínima da faixa dessas estruturas de $100 \mathrm{~m}$ (70 m mais $30 \mathrm{~m})$ para $80 \mathrm{~m} \mathrm{(50} \mathrm{m} \mathrm{mais}$ $30 \mathrm{~m}$ ) em cada margem. Analogamente, torna-se ainda mais inadequado o processo de revogação com revisão do PD em 2014, pois as alterações 
nele promovidas diminuem o efeito de renaturalização e integração entre os corredores ecológicos (SNUC), que deveriam ter sido instituídos pelo município, e os Ciecos urbanos, como estruturas de continuidade de biomas naturais na escala regional e urbana.

A expressão "corredor de integração ecológica", utilizada na $\mathrm{LC} \mathrm{n}^{\circ} 350$ de 27 de dezembro de 2005 (PREFEITURA..., 2005) do PD, é muito clara sobre a definição, os objetivos e as finalidades dos Ciecos, nos artigos 110 e 111, considerando os seguintes elementos:

(a) a instituição de uma faixa de $100 \mathrm{~m}$ de cada lado da rede hídrica como elemento estruturador, devido ao impacto ambiental previsto no Atlas Ambiental Urbano de Araraquara (Aura) e disposto no Mape 4 - Zoneamento Ambiental de Área de Basalto (em azul escuro na Figura 2). $\mathrm{Na}$ $\mathrm{LC}^{\circ} 850 / 2014$, a faixa foi reduzida para $70 \mathrm{~m} \mathrm{e}$ retirou-se a menção ao impacto ambiental previsto no Mape 4;

(b) a faixa de $30 \mathrm{~m}$ de APP, sujeita à legislação federal (Lei $\mathrm{n}^{\circ}$ 12.651/2012 (BRASIL, 2012)), como área non-aedificandi, passível de ações de proteção, preservação e recuperação de mata ciliar;

(c) a faixa de $70 \mathrm{~m}$ adicional, como área nonaedificandi, com usos permitidos para a implantação exclusiva de parques lineares urbanos (ou seja, usos que permitam ampliar a noção de áreas verdes, uma renaturalização, além da cobertura arbórea da APP, mesmo que incorpore equipamentos de recreação social condicionada nessas áreas). Esse conceito é consoante à "Declaração do Rio Princípio 4", da Conferência sobre Meio Ambiente e Desenvolvimento, a ECO92, que apresenta a proteção do meio ambiente integrada ao processo de desenvolvimento, e não considerada isoladamente. Também é consoante à Agenda 21, que associa os ecossistemas ao bemestar e à qualidade de vida da população (MP-RS, 2015). Dessa forma, é concebível o pensamento de conservação e manejo mais adequados dos ecossistemas e de qualidade de vida mais digna, associados à integração dos Ciecos aos meios físico e social do município, superando o conceito pragmático do isolamento estritamente preservacionista e proporcionando a incorporação de valores socioambientais à cultura dos cidadãos;

(d) como um fato inédito em planos diretores, o PD de 2005 instituiu as redes hídricas e Ciecos como elementos estruturadores do modelo espacial e sistema urbano municipal; e

(e) nos Ciecos Ribeirão das Cruzes e do Ouro, o PD de 2005 fez uma ampliação apenas da necessidade de vinculação estratégica entre os objetivos do Ciecos (parques lineares urbanos), com os de implantar a estrutura de mobilidade sustentável no município (Mape 7), ao instituir os corredores estruturais de urbanidade (CEU) ou o novo conceito de avenidas-parques, termo muito utilizado no modelo do urbanismo moderno e culturalista das cidades-jardins, em que o município de Araraquara tem uma ligação histórico-cultural devido ao Relatório da Câmara Municipal de 1911. Este poderia ser apontado como o primeiro PD do município, considerando a importância do assunto e o seu desígnio como princípio fundador.

Após a revogação com revisão do PD em 2014, os Ciecos passaram a ter uma definição muito aquém ao apresentado no PD de 2005, o que poderia levantar sérios questionamentos sobre as atuais atribuições dessas estruturas e, principalmente, sobre os motivos que justificaram essas mudanças pela LC no 850/2014 (PREFEITURA..., 2014a). A faixa de $100 \mathrm{~m}$ de cada lado da rede hídrica, inicialmente instituída pelo PD de 2005, possuía, claramente, uma função de proteção e recuperação dos recursos hídricos e do solo das microbacias. As formações de basalto, predominantes às margens das redes hídricas, possuem características de fragilidade ambiental mais elevadas e com maior suscetibilidade à contaminação das águas subterrâneas por meio da exposição do aquífero à superfície ou às formações geológicas mais jovens, por fraturas ou "janelas" no basalto (ORGANIZAÇÃO..., 2009).

\section{Materiais e métodos}

Para a realização desta pesquisa, foram utilizados mapas georreferenciados da hidrografia de Araraquara, contendo os cursos d'água, as APPs, os fragmentos vegetais e as nascentes, mapeados pela Secretaria Municipal do Meio Ambiente (SMMA) (PREFEITURA..., 2014b; ARAÚJO NETO, 2012a, 2012b). Ademais, foram utilizados os dados e informações obtidos no PD de 2014 , além de consulta à Lei $n^{\circ} 12.651 / 2012$ (BRASIL, 2012). Esses dados integrados ao SIG foram utilizados para as análises espaciais e elaboração de mapas temáticos, com auxílio das imagens orbitais do Google Earth, do ano de 2014. A utilização do SIG foi importante, pois permitiu a análise em todo o perímetro urbano do município, integrando diferentes bases de dados espaciais em um único sistema de coordenadas. Tal ferramenta possibilitou sobreposições espaciais das estruturas das APPs e dos Ciecos segundo o PD de 2014, e dessas estruturas físicas existentes, mapeadas pela SMMA, além da identificação de possíveis usos e ocupações nessas faixas por meio das imagens de satélite. 
Figura 2 - Mape 4 (PD de 2005) - Zoneamento Ambiental

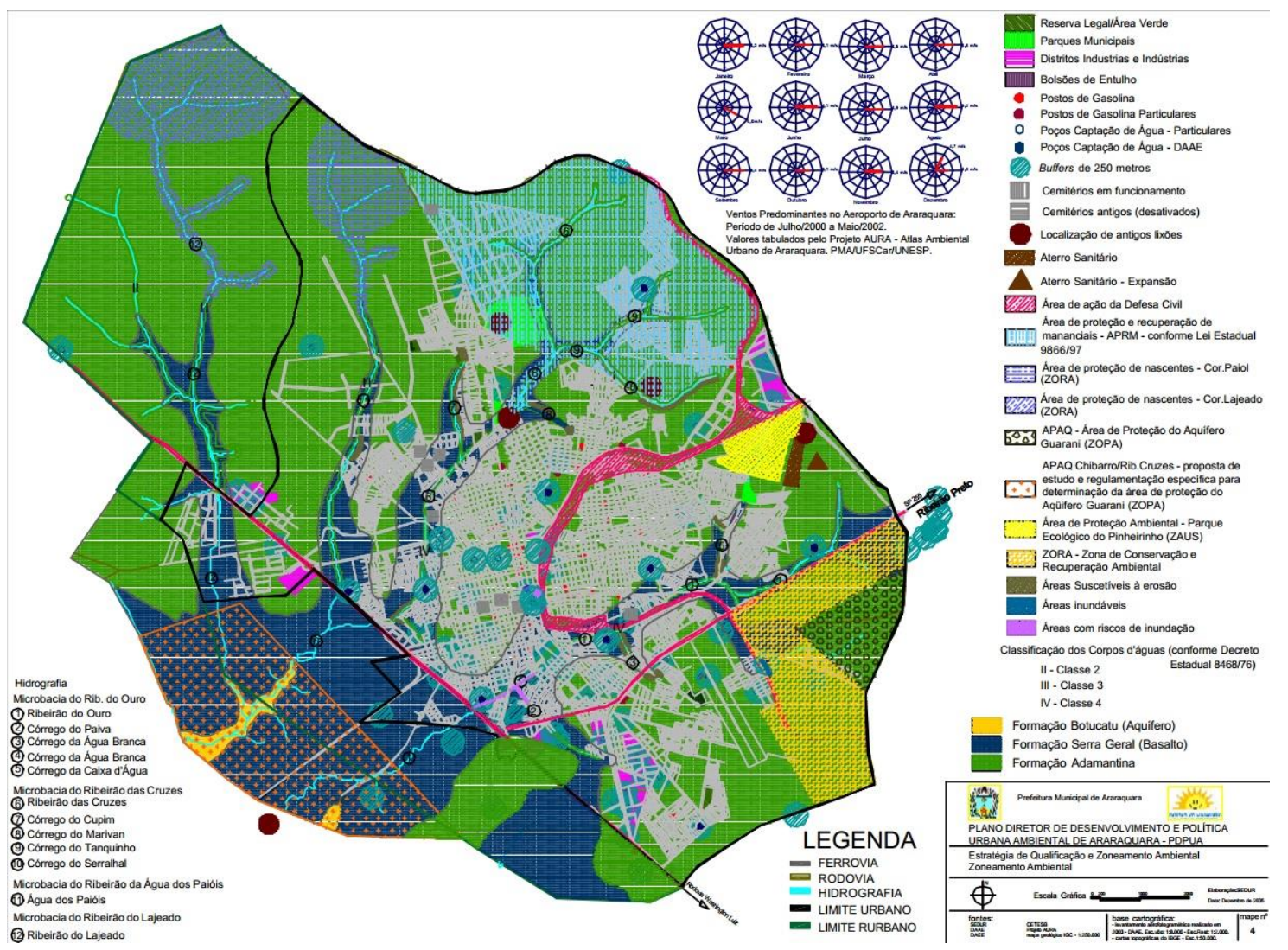

Fonte: Anexo I da Lei complementar n 350 de dezembro de 2005 do PD de Araraquara (PREFEITURA..., 2005).

Todos os dados e imagens foram manipulados na Projeção UTM, Datum SAD/69, Meridiano Central: $51^{\circ} \mathrm{WGr}$. Para a integração de todas essas bases de dados foi utilizado o software QGis, versão 2.8.1, de licença livre e interface intuitiva, que facilitou sua aplicação e aprendizado. Foram realizadas entrevistas com um dos responsáveis pela Gerência de Monitoramento da Qualidade Ambiental (GMQA) da Secretaria Municipal do Meio Ambiente (SMMA), e também com um dos responsáveis pela coordenação da Secretaria de Planejamento Urbano (SPU). Essas entrevistas auxiliaram na análise, interpretação dos dados e principalmente na elucidação de dúvidas decorrentes do estudo.

\section{Mapeamento das estruturas da hidrografia urbana de Araraquara}

\section{Estudo dos mapas estratégicos do PD}

Foi realizada uma comparação integrando os dados espaciais extraídos dos mapas estratégicos (Mapes) do PD de 2014 e dos cursos d'água e nascentes do mapa da hidrografia urbana da SMMA (PREFEITURA ..., 2014b). Aplicando um buffer de $30 \mathrm{~m}$ representativo das APPs ciliares, em ambas as margens da hidrografia, e de $50 \mathrm{~m}$ nas nascentes perenes - conforme a delimitação mínima da Lei no 12.651/2012 - (BRASIL, 2012), e também conforme especificação do PD, foi possível identificar alguns trechos que não haviam sido representados nos Mapes, possibilitando assim a atualização e complementação desses dados, que serviram de parâmetro de análise. No caso dos Ciecos, suas áreas foram apenas extraídas do Mape $n^{\circ} 4$ e não houve atualizações. Segundo a SPU, essas estruturas foram definidas respeitando as áreas urbanas consolidadas. Destaca-se que o Córrego da Servidão, que está canalizado e não foi representado nos Mapes, foi desprezado nessa análise. Além disso, apenas as nascentes perenes foram incluídas no buffer de $50 \mathrm{~m}$, pois a interpretação da Lei $\mathrm{n}^{\circ}$ 12.651/2012 (BRASIL, 2012), art. $4^{\text {o }}$, inciso IV, sugere que as nascentes intermitentes não possuem obrigatoriedade de dispor de APP.

As áreas obtidas foram de 492,2 ha para as APPs ciliares e de 514,4 ha para os Ciecos, como mostra a Tabela 1, sendo estas adotadas como $100 \%$ dessas estruturas. 
Tabela 1 - Áreas das APPs e dos Ciecos urbanos - PD de 2014 com os dados atualizados da SMMA

\begin{tabular}{c|c|c|c}
\hline \multirow{2}{*}{ REDE HÍDRICA } & PLANO & GMQA - & PLANO \\
& DIRETOR (ha) & SMMA (ha) & DIRETOR (ha) \\
\cline { 2 - 4 } & APP - MAPE 4 & APP - 2014 & CIECO - MAPE 7 \\
\hline Ribeirão do Lageado & 17,9 & 0,0 & 20,6 \\
Ribeirão das Cruzes e afluentes & 291,8 & 5,7 & 435,6 \\
Ribeirão do Ouro e afluentes & 144,5 & 23,1 & 42,6 \\
Córrego do Capaúva & 7,0 & 0,0 & 15,5 \\
Córrego da Água Azul & 0,0 & 2,1 & 0,0 \\
\hline \multirow{2}{*}{ ÁREA TOTAL (ha) } & $\mathbf{4 6 1 , 3}$ & $\mathbf{3 0 , 9}$ & \multirow{2}{|c|}{$\mathbf{4 9 2 , 2}$} \\
\cline { 2 - 4 } & \multicolumn{2}{|c|}{} \\
\hline
\end{tabular}

\section{Estudo das APPs e dos Ciecos existentes}

A base de dados espaciais da SMMA consistiu, inicialmente, do tratamento espectral de imagem do satélite QuickBird de 2006, que possibilitou o mapeamento temático das redes hídricas, dos maciços arbóreos e dos fragmentos vegetais do perímetro urbano. Desde então, essa base de dados vem sendo atualizada e complementada por meio dos trabalhos de mapeamento de campo realizados pela SMMA, com equipamento de posicionamento por navegação, ou seja, sem precisão de georreferenciamento, sendo sua última atualização datada do ano 2014.

Com esses mapas, foi possível realizar uma sobreposição com as feições extraídas dos Mapes do PD de 2014 (Figura 3) e, a partir daí, isolar essas estruturas existentes localizadas dentro das faixas de estudo. A área total obtida dos trechos das APPs vegetadas existentes foi de 225,7 ha para todo o perímetro urbano, ou seja, $45,9 \%$ do valor ideal calculado de 492,2 ha. Nos Ciecos, a área total dos fragmentos de vegetação dispostos nesses corredores foi de 176,9 ha, que corresponde a $34,4 \%$ da área total de 514,4 ha.

A Figura 3 ilustra a disposição dessas estruturas no perímetro urbano e a Tabela 2 apresenta a relação das áreas calculadas em cada trecho.

A partir dessa análise, constatou-se que $54,1 \%$ das APPs da hidrografia urbana e $65,6 \%$ dos Ciecos previstos no PD de 2014 não possuem cobertura de vegetação com características de matas ciliares ou maciços vegetais. Apesar de essas estruturas não terem sido consideradas como vegetadas, elas poderiam apresentar características de várzeas alagáveis ou com algum tipo de vegetação rasteira, e não necessariamente estariam atribuídas totalmente a usos antrópicos ou áreas urbanas consolidadas.

\section{Estudo das áreas urbanas consolidadas e de uso antrópico}

Em complementação ao apresentado anteriormente, foi realizada outra análise das áreas não vegetadas, com utilização de imagens de satélite do Google Earth (complemento OpenLayers do QGis). Essas imagens, datadas entre 9/5/2014 e 5/11/2014, permitiram uma análise visual, com precisão adequada ao estudo, das ocupações das faixas de Cieco e de APP.

Apesar de as imagens utilizadas proporcionarem uma grande automação no processo de mapeamento de áreas aparentemente ocupadas, em alguns casos não foi possível classificar de maneira evidente e acurada todas as estruturas objeto deste estudo. Cabe evidenciar uma ressalva sobre as limitações do processo que, além de não apresentar precisão de georreferenciamento, eventualmente pode induzir o observador a uma classificação que não representa plenamente a realidade física. A indefinição que se fez mais presente durante o processo de mapeamento, que representaria quase a totalidade das incertezas deste estudo, refere-se à correta classificação das áreas não ocupadas, no que concerne à distinção entre áreas forrageiras com atividades agropastoris, ou à sucessão natural posterior ao abandono dessas áreas, com vegetação espontânea em processo de regeneração (capoeira).

A capoeira é um tipo de vegetação secundária ou em regeneração, "[...] resultante de processos de sucessão, após supressão total ou parcial de vegetação primária por ações antrópicas ou causas naturais, podendo ocorrer árvores remanescentes de vegetação primária [...]" (BRASIL, 1994, p. 1). As capoeiras possuem funções ecológicas que auxiliam na conservação do solo e da diversidade de plantas e animais, de modo que a idade e o estágio de desenvolvimento desse tipo de vegetação estão relacionados à fertilidade do solo, ao tipo de vegetação primária anterior e ao histórico de uso da terra (RIOS et al., 2001). 
Figura 3 - Mapa das APPs e Ciecos ocupadas por vegetação

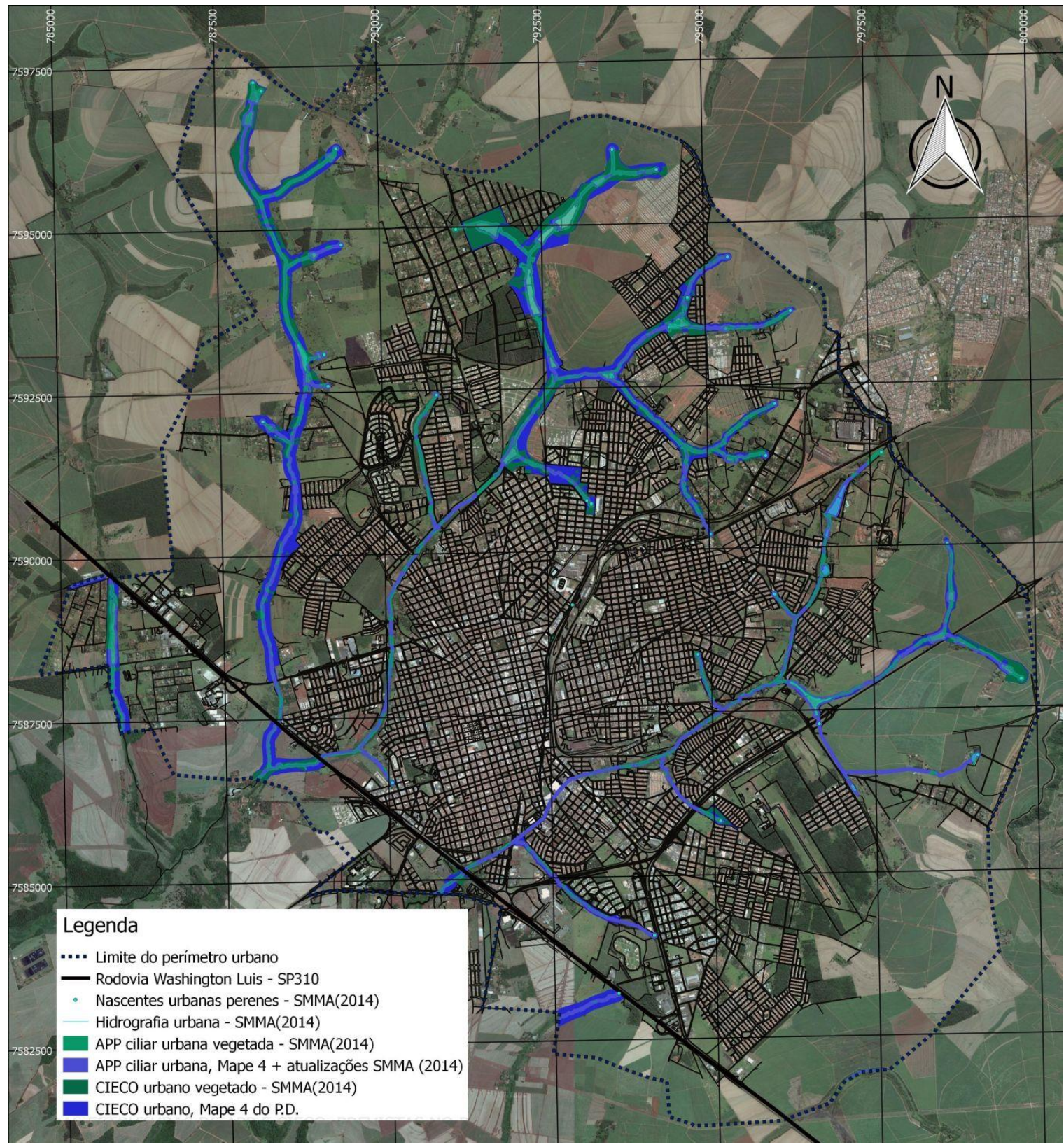

Tabela 2 - APPs ciliares e Ciecos vegetados urbanos existentes segundo dados da SMMA

\begin{tabular}{c|c|c|c|c}
\hline \multirow{2}{*}{ REDE HÍDRICA } & $\begin{array}{c}\text { GMQA - } \\
\text { SMMA (ha) }\end{array}$ & Ocupação & $\begin{array}{c}\text { GMQA - } \\
\text { SMMA (ha) }\end{array}$ & Ocupação \\
\cline { 2 - 4 } & $\begin{array}{c}\text { APP CILIAR } \\
\text { vegetada }\end{array}$ & Vegetal & $\begin{array}{c}\text { CIECO } \\
\text { vegetado }\end{array}$ & Vegetal \\
\hline Ribeirão do Lageado & 14,4 & $80,5 \%$ & 5,3 & $25,8 \%$ \\
\hline Ribeirão das Cruzes e afluentes & 160,1 & $53,8 \%$ & 155,1 & $35,6 \%$ \\
\hline Ribeirão do Ouro e afluentes & 50,6 & $30,2 \%$ & 16,4 & $38,5 \%$ \\
\hline Córrego do Capaúva & 0,2 & $2,2 \%$ & 0,0 & $0,0 \%$ \\
\hline Córrego da Água Azul & 0,4 & $18,5 \%$ & 0,0 & $0,0 \%$ \\
\hline ÁREA TOTAL (ha) & $\mathbf{2 2 5 , 7}$ & $\mathbf{4 5 , 9 \%}$ & $\mathbf{1 7 6 , 9}$ & $\mathbf{3 4 , 4 \%}$ \\
\hline
\end{tabular}


Todavia, o desenvolvimento das capoeiras não está atrelado incondicionalmente ao histórico antropocêntrico, de tal forma que um manejo adequado também pode auxiliar na regeneração espontânea dessa cobertura vegetal. Desse modo, visando aprofundar a análise e proporcionar uma visão mais condizente com a atual realidade das estruturas de APP e Cieco urbanos, foi realizada uma série de vistorias em campo, por amostragem não aleatória e seletiva, para possibilitar uma melhor discriminação entre vegetação forrageira e vegetação espontânea (capoeira), assim como verificar os estágios de regeneração com embasamento na Resolução Conama no 28/1994.

As interferências com as faixas do estudo foram classificadas em seis tipos de ocupação:

(a) chácaras de recreio e afins - são grandes propriedades urbanas (maiores que lotes, por exemplo) com características de moradia, lazer ou até mesmo pequenos cultivos;

(b) uso antrópico agropecuário - são grandes propriedades urbanas com características agropastoris, de cultivos variados ou com instalações de uso agrícola;

(c) edificações isoladas - são ocupações com edificações, residenciais, comerciais ou industriais que não estão dispostas em nenhuma quadra parcelada;

(d) urbano consolidado - são áreas loteadas, com grandes intervenções urbanas (avenidas marginais, canais e valas artificiais), etc.;

(e) vias pavimentadas e afins - são pontes, rodovias e demais vias de circulação pavimentadas, e também estradas não pavimentadas, porém bem definidas; e

(f) APP/Cieco não ocupados - são áreas com vegetação secundária (capoeira), e que não se enquadraram como vegetadas pela SMMA.

Foi possível identificar que dos $54,1 \%$ das faixas de APP não vegetadas (266,5 ha), 35,7\% (175,7 ha) possuíam vegetação espontânea em algum estágio de regeneração e não apresentaram características de ocupação ou de uso antrópico recentes. Estas estariam, de alguma forma, contribuindo para a preservação das redes hídricas, mesmo sem possuir vegetação primária. Ou seja, da área total estimada para as estruturas urbanas de APP, $81,6 \%$ estaria recoberta por algum tipo de vegetação ciliar primária $(45,9 \%)$ ou apresentaria características de capoeira $(35,7 \%)$, como mostra a Tabela 3.
Segundo a amostragem realizada nas APPs classificadas como "não ocupadas" (175,7 ha), $68 \%$ dos locais investigados encontravam-se em estágio inicial de regeneração, $30 \%$ em estágio médio de regeneração e $2 \%$ eram compostos por várzeas alagadiças (brejos).

Os três principais tipos de uso ou ocupação observados nas faixas de APPs foram:

(a) agropecuários com 54,1 ha (11,0\%), com predominância agropastoril e de cultivo de canade-açúcar, principalmente no Ribeirão das Cruzes e no Ribeirão do Ouro, assim como em seus afluentes, porém cabe uma observação quanto à ocupação agropastoril. Aproximadamente 12,7 ha seriam compreendidos pela utilização parcial de faixas de APP em regiões socialmente vulneráveis, onde é muito frequente a prática da exploração animal como meio de transporte, e não foram consideradas como em atividade agropastoril. Nesses casos, a vegetação apresentou características mistas de capoeira e de pastagem devido à subutilização da forragem para alimentação de apenas um ou dois animais por área. Se essas fossem consideradas como pastagens artificiais, a taxa de ocupação desta classe seria de aproximadamente $13,5 \%$;

(b) rodovias, pontes e demais vias de circulação com 15,3 ha $(3,1 \%)$ distribuídas em todo o perímetro urbano, sendo aproximadamente um quinto desse número compreendido por estradas de terra bem definidas; $\mathrm{e}$

(c) espaços urbanos consolidados com 10,5 ha $(2,1 \%)$, sendo mais de dois terços dessa área correspondente apenas à região de confluência do Ribeirão do Ouro com os Córregos da Servidão e Capão do Paiva, onde aproximadamente $1.000 \mathrm{~m}$ da extensão do curso do Ribeirão do Ouro se desenvolvem entre avenidas marginais e $450 \mathrm{~m}$ encontram-se canalizados sob as instalações da sede administrativa da Sucocítrico Cutrale Ltda., uma importante indústria que atua principalmente no processamento e envasamento de suco de laranja e seus subprodutos para exportação. Estima-se que a Cutrale controla mais de um terço do mercado mundial de suco de laranja (KASKEY; DOYLE, 2014)

Nos Ciecos classificados como "não ocupados" (129,8 ha), a amostragem apontou que $84 \%$ dos locais investigados encontravam-se em estágio inicial de regeneração e $16 \%$ em estágio médio de regeneração. 
Tabela 3 - APPs ciliares urbanas não vegetadas - análise dos tipos de ocupação

\begin{tabular}{|c|c|c|c|c|c|c|c|c|c|c|c|c|}
\hline \multirow{2}{*}{ REDES HÍDRICAS } & \multicolumn{2}{|c|}{$\mathbf{I}$} & \multicolumn{2}{|c|}{ II } & \multicolumn{2}{|c|}{ III } & \multicolumn{2}{|c|}{ IV } & \multicolumn{2}{|c|}{$\mathbf{V}$} & \multicolumn{2}{|c|}{ VI } \\
\hline & (ha) & $(\%)$ & (ha) & $(\%)$ & (ha) & $(\%)$ & (ha) & $(\%)$ & (ha) & $(\%)$ & (ha) & $(\%)$ \\
\hline Ribeirão do Lageado & 0,3 & 1,6 & 1,8 & 9,9 & 0,0 & 0,0 & 0,0 & 0,0 & 0,0 & 0,0 & 1,4 & 7,9 \\
\hline Ribeirão das Cruzes e afluentes & 5,6 & 1,9 & 19,4 & 6,5 & 0,0 & 0,0 & 0,3 & 0,0 & 6,5 & 2,2 & 105,5 & 35,4 \\
\hline Ribeirão do Ouro e afluentes & 3,5 & 2,1 & 29,2 & 17,4 & 1,4 & 0,8 & 10,2 & 6,1 & 8,3 & 4,9 & 63,7 & 38,0 \\
\hline Córrego do Capaúva & 0,0 & 0,0 & 2,5 & 35,1 & 0,0 & 0,0 & 0,0 & 0,0 & 0,5 & 7,5 & 3,9 & 55,2 \\
\hline Córrego da Água Azul & 0,0 & 0,0 & 1,2 & 57,3 & 0,0 & 0,0 & 0,0 & 0,0 & 0,0 & 0,0 & 0,5 & 24,3 \\
\hline ÁREA TOTAL (ha) & 9,4 & 1,9 & 54,1 & 11,0 & $\mathbf{1 , 5}$ & $\mathbf{0 , 3}$ & $\mathbf{1 0 , 5}$ & 2,1 & 15,3 & $3, \mathbf{1}$ & 175,7 & 35,7 \\
\hline APP NÃO VEGETADA (ha) & \multicolumn{9}{|c|}{266,5} & \multicolumn{3}{|c|}{$54,1 \%$} \\
\hline $\begin{array}{l}\text { Nota: Legenda: } \\
\text { I - Chácaras de recreio e } \\
\text { II - Uso antrópico agrope } \\
\text { III - Edificações isoladas; } \\
\text { IV - Urbano consolidado; } \\
\text { V - Vias pavimentadas e } \\
\text { VI - APP não ocupada. }\end{array}$ & $\begin{array}{l}\text { ns; } \\
\text { rio; } \\
\text { ss; e }\end{array}$ & & & & & & & & & & & \\
\hline
\end{tabular}

Tabela 4 - Ciecos urbanos não vegetados - análise dos tipos de ocupação

\begin{tabular}{|c|c|c|c|c|c|c|c|c|c|c|c|c|}
\hline \multirow{2}{*}{ REDES HÍDRICAS } & \multicolumn{2}{|c|}{$\mathbf{I}$} & \multicolumn{2}{|c|}{ II } & \multicolumn{2}{|c|}{ III } & \multicolumn{2}{|c|}{ IV } & \multicolumn{2}{|c|}{$\overline{\mathrm{V}}$} & \multicolumn{2}{|c|}{ VI } \\
\hline & (ha) & $(\%)$ & (ha) & $(\%)$ & (ha) & $(\%)$ & (ha) & $(\%)$ & (ha) & $(\%)$ & (ha) & $(\%)$ \\
\hline Ribeirão do Lageado & 3,0 & 14,7 & 0,0 & 0,0 & 0,5 & 2,3 & 0,0 & 0,0 & 0,6 & 2,9 & 11,2 & 54,3 \\
\hline Ribeirão das Cruzes e afluentes & 28,6 & 6,6 & 130,5 & 30,0 & 5,5 & 1,3 & 12,3 & 2,8 & 6,0 & 1,4 & 97,7 & 22,4 \\
\hline Ribeirão do Ouro e afluentes & 0,9 & 2,2 & 4,4 & 10,2 & 1,4 & 3,3 & 0,0 & 0,0 & 0,3 & 0,6 & 19,2 & 45,1 \\
\hline Córrego do Capaúva & 0,0 & 0,0 & 13,9 & 89,4 & 0,0 & 0,0 & 0,0 & 0,0 & 0,0 & 0,0 & 1,6 & 10,6 \\
\hline Córrego da Água Azul & \multicolumn{12}{|c|}{ NÃO POSSUI CIECO PREVISTO NO PLANO DIRETOR } \\
\hline ÁREA TOTAL (ha) & 32,6 & 6,3 & 148,7 & 28,9 & $\mathbf{7 , 3}$ & 1,4 & 12,3 & 2,4 & 6,8 & 1,3 & 129,8 & 25,2 \\
\hline CIECO NÃO VEGETADO & \multicolumn{9}{|c|}{337,5} & \multicolumn{3}{|c|}{$65,6 \%$} \\
\hline $\begin{array}{l}\text { Nota: Legenda: } \\
\text { I - Chácaras de recreio e a } \\
\text { I I- Uso antrópico agropec } \\
\text { III - Edificações isoladas; } \\
\text { IV - Urbano consolidado; } \\
\text { V - Vias pavimentadas e a } \\
\text { VI - CIECO não ocupado. }\end{array}$ & $\begin{array}{l}\text { fins; } \\
\text { tário; } \\
\text { ins; e }\end{array}$ & & & & & & & & & & & \\
\hline
\end{tabular}

Ao todo, as três maiores incidências de ocupação ou uso identificadas nas faixas de Ciecos seriam:

(a) agropecuário com 148,7 ha $(28,9 \%)$ e, assim como observado nas APPs, com predominância agropastoril e de cultivo de cana-de-açúcar. Porém, as maiores incidências desse tipo foram encontradas no Córrego Água dos Paióis, a oeste do perímetro urbano;

(b) chácaras, ou similares, com 32,6 ha $(6,3 \%)$, com maiores incidências no Córrego Água dos Paióis e no Ribeirão das Cruzes e seus afluentes; e

(c) espaços urbanos consolidados com 12,3 ha $(2,4 \%)$, com destaque para as estruturas de estabilidade de encostas e drenagem urbana em construção, dos conjuntos habitacionais Jardim do Valle e Jardim Valle Verde, localizados no extremo norte do perímetro urbano, que contemplam 1.992 casas populares dos Programas Minha Casa Minha Vida e Casa Paulista.
Lembrando que o Córrego da Servidão, atualmente canalizado em todo o seu curso (sob a Av. Maria Antônia Camargo de Oliveira), não está disposto nos Mapes do PD de 2005 ou de 2014. Apenas para conhecimento, as estruturas de APP em toda a extensão desse curso d'água deveriam corresponder a uma área de aproximadamente 20,3 ha.

Isso reflete uma realidade recorrente em todo o país, onde o crescimento da cidade em função do incentivo à expansão da malha viária em detrimento da manutenção das áreas naturais resultou no confinamento de córregos e na ocupação e impermeabilização das áreas de várzea, o que acarretou diversos problemas de inundação e enchentes urbanas. Esses problemas poderiam ter sido evitados com uma regulamentação efetiva do uso do solo, limitando a ocupação de áreas de várzea para usos de preservação e conservação ambiental, reflorestamentos e integração de fragmentos vegetais, além de usos que favoreçam a

16 Menzori, I. D.; Falcoski, L. A. N. 
consolidação de valores socioambientais, como os parques lineares, por exemplo. A LC no 350 do PD de 2005 apresentou uma grande inovação ao instituir as redes hídricas e os Ciecos como elementos estruturadores do espaço urbano. As faixas adicionais de $70 \mathrm{~m}$ dos Ciecos tornaram-se áreas non-aedificandi, com usos permitidos apenas para parques lineares urbanos que, além de promoverem a preservação ambiental e a reapropriação dos espaços públicos pelas pessoas em oposição ao viés do isolamento estritamente preservacionista -, inibem a degradação do meio ambiente (como o despejo de entulho em áreas verdes, por exemplo) e contribuem diretamente no controle do escoamento superficial e da vazão dos cursos d'água durante as chuvas.

A Figura 4 ilustra a disposição espacial das ocupações e dos usos observados.

\section{Figura 4 - Mapa das ocupações observadas nas imagens Google Earth de 2014}

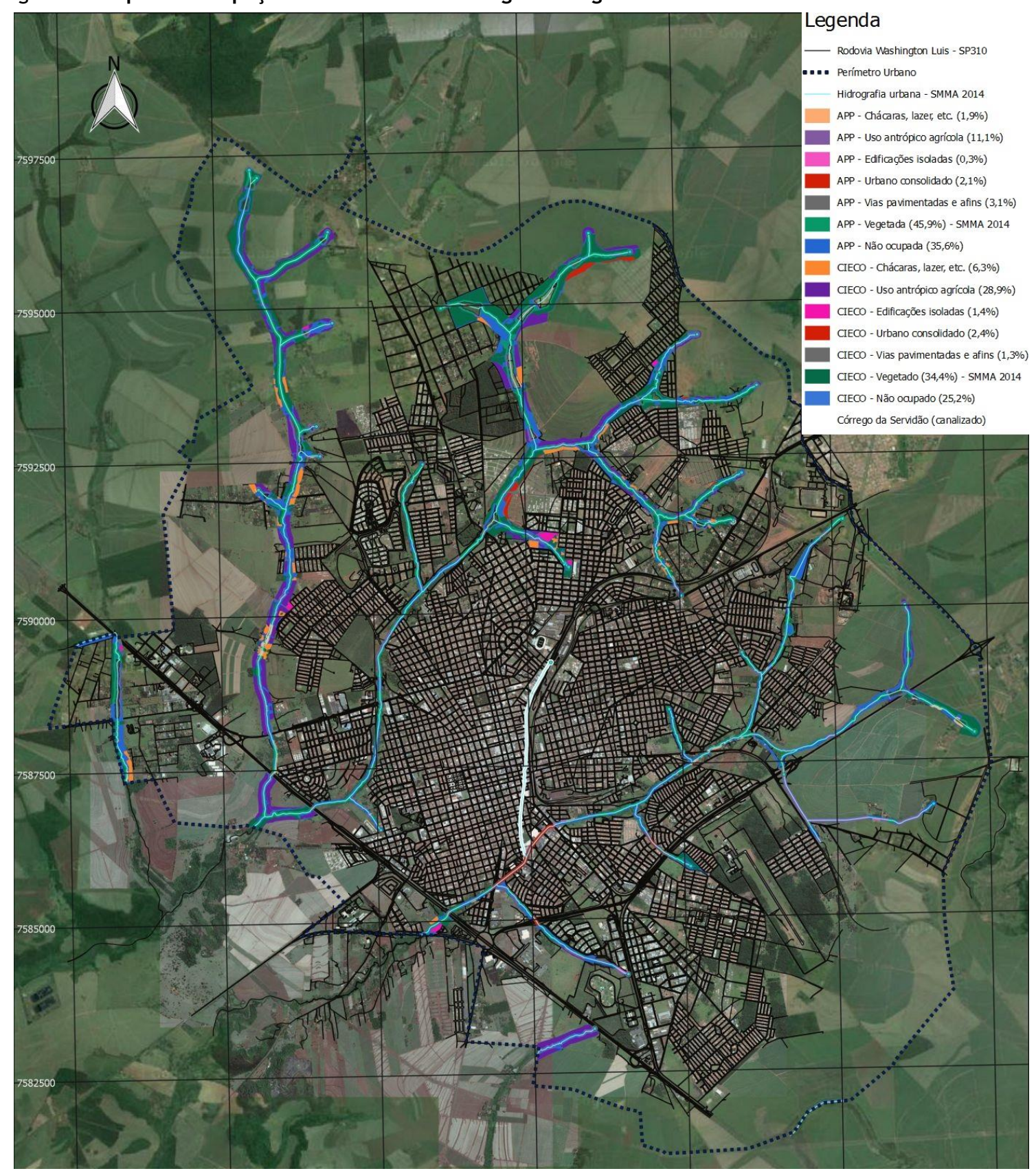




\section{Conclusão}

A Prefeitura de Araraquara, por meio da SMMA, busca o aperfeiçoamento e a qualificação de seus colaboradores, em que o SIG contribui com ferramentas para a execução de mapas para o planejamento de ações de recuperação e preservação do meio ambiente. Os trabalhos de monitoramento ambiental, realizados pela SMMA, estão em constante desenvolvimento, com esforços na busca por uma base de dados espacial adequada à dinâmica vegetacional, que contribui para uma eficiente gestão ambiental do município.

A última revogação com revisão das políticas ambientais do PD, pela LC $\mathrm{n}^{\circ} 850$ de 11 de fevereiro de 2014 (PREFEITURA..., 2014a), acrescentou uma nova definição para os Ciecos, em que essas estruturas teriam uso permitido para algumas finalidades específicas, com diminuição da largura de faixa para $50 \mathrm{~m}$ além da APP $(30 \mathrm{~m})$ em cada margem - aparentemente desprezando o impacto ambiental previsto no Aura e disposto no Mape $\mathrm{n}^{\circ} 4$ do PD de 2005 -, e negligenciando a preocupação com a suscetibilidade à contaminação das águas subterrâneas do Aquífero Guarani, uma importante reserva estratégica para o abastecimento da população e para o desenvolvimento de atividades econômicas. Conclui-se que essas estruturas sofreram uma mudança de "status", em que os tipos de uso foram liberalizados e passaram a apresentar alta permissividade a projetos que descaracterizam a noção de parque linear urbano e, além disso, reduzem as contribuições dessas estruturas na proteção e recuperação dos recursos naturais e nos processos de integração e renaturalização entre os corredores ecológicos (que deveriam ter sido instituídos pelo município) e os Ciecos urbanos.

O índice de interferências nas faixas de APPs pode ser considerado como surpreendente. Apesar de apenas $45,9 \%$ dessas estruturas apresentarem vegetação com características de mata ciliar primária, no total, $81,6 \%$ estariam respeitando as faixas mínimas previstas com algum tipo de vegetação intacta ou resultante de processos naturais de sucessão, sem uso antrópico recente identificado. Os destaques principais estão nas APPs do Ribeirão das Cruzes (com 89,3\% sem uso identificado) e do Ribeirão do Ouro (com 68,6\% sem uso identificado) que, juntos e com seus respectivos afluentes, correspondem a 94,5\% de todas as APPs previstas para o perímetro urbano.

Já nos Ciecos a situação não surpreende, ao menos não de forma positiva. Apesar de essas estruturas terem sido previstas em maior quantidade em regiões periféricas ou, no mínimo, evitando espaços urbanos mais ocupados e, mesmo com a redução da largura de faixa de $70 \mathrm{~m}$ para $50 \mathrm{~m}$ (promovida pela LC $\mathrm{n}^{\circ} 850 / 2014$ ), apenas $34,4 \%$ foram consideradas como vegetadas e, no total, $59,6 \%$ estariam respeitando as extensões mínimas definidas com algum tipo de vegetação primária ou secundária, sem uso antrópico identificado.

Talvez esses indicadores observados sejam reflexo da pouca importância atribuída pelo município aos Ciecos e, consequentemente, às redes hídricas, em que a revogação com revisão do PD de 2014, da maneira como foi realizada, poderia representar um retrocesso enorme na busca pelo ecodesenvolvimento. Apesar de as estruturas, objeto deste estudo, estarem diretamente atreladas à questão dos recursos hídricos - em que as responsabilidades se dividem entre a União e os Estados, pois, legalmente, não existem águas de domínio municipal -, permanece válida a crítica ao poder público municipal pela alteração promovida em elementos estruturantes do espaço urbano ambiental. Embora a gestão hídrica não seja encargo do município, a prefeitura é responsável pela gestão do meio ambiente e do uso e ocupação do solo em benefício da preservação do patrimônio hídrico - no qual a importância dos Ciecos reside também nas atribuições de preservação de áreas com constatada fragilidade ambiental, conforme apresentado anteriormente.

Aliada a essas questões, uma fiscalização insuficiente ou inexistente sobre o avanço na ocupação das APPs e dos Ciecos, em conjunto a uma possível permissividade do poder público municipal na ocupação dessas estruturas, poderia indicar uma realidade de desenvolvimento urbano que não considera as questões ambientais, isto é, negligenciando fatores inerentes à qualidade de vida dos cidadãos (como a gestão dos recursos hídricos que está atrelada diretamente à preservação da mata ciliar e da vegetação de cabeceira), indo na contramão dos importantes trabalhos desenvolvidos pela SMMA do mesmo município. Analisando por essa perspectiva, essas estruturas ambientais urbanas dificilmente terão sua importância efetivamente reconhecida pela população, o que torna sua incorporação à cultura dos cidadãos araraquarenses uma realidade ainda mais distante de ser alcançada.

\section{Referências}

ARAÚJO NETO, L.; DANTAS, G. C.; LIRA, D. B. A análise Ambiental no Município de Araraquara-SP. In: SIMPÓSIO DE TECNOLOGIAS EM MEIO AMBIENTE, 4, Jaú, 2012. In: SIMPÓSIO DE TECNOLOGIA EM MEIO AMBIENTE, RECURSOS HÍDRICOS, 4., Jaú, 2012. Anais... Jaú: FATEC, 2012a. 
ARAÚJO NETO, L.; DANTAS, G. C.; LIRA, D. B. Mapeamento de Nascentes no Município de Araraquara-SP. In: SIMPÓSIO DE TECNOLOGIAS EM MEIO AMBIENTE, 4.; SIMPÓSIO DE TECNOLOGIA EM MEIO AMBIENTE, RECURSOS HÍDRICOS, 4., Jaú, 2012. Anais... Jaú: FATEC, 2012b.

BRASIL. Conselho Nacional do Meio Ambiente. Resolução no 1, de 31 de janeiro de 1994. 1994. Disponível em:

<http://www.mma.gov.br/port/conama/res/res94/re s0194.html>. Acesso em: 4 fev. 2016.

BRASIL. Lei $\mathrm{n}^{\circ} 12.651$, de 25 de maio de 2012, que dispõe sobre a proteção da vegetação nativa; altera as Leis nos 6.938, de 31 de agosto de 1981, 9.393, de 19 de dezembro de 1996, e 11.428, de 22 de dezembro de 2006; revoga as Leis nos 4.771, de 15 de setembro de 1965 , e 7.754 , de 14 de abril de 1989, e a Medida Provisória no 2.166-67, de 24 de agosto de 2001; e dá outras providências. Diário Oficial da União, 26 de maio de 2012.

BRASIL. Lei ${ }^{\circ} 9.985$, de 18 de julho de 2000, que regulamenta o art. $225, \S 10$, incisos I, II, III e VII da Constituição Federal, institui o Sistema Nacional de Unidades de Conservação da Natureza e dá outras providências. Diário Oficial da União, 20 de julho de 2000.

BRASIL. Ministério do Meio Ambiente. Corredores Ecológicos. Disponível em: $<$ http://www.mma.gov.br/areas-protegidas/acoese-iniciativas/gestao-territorial-para-aconservacao/corredores-ecologicos>. Acesso em: 12 maio 2015.

FALCOSKI, L. A. N. Plano Diretor de Desenvolvimento Urbano Ambiental de Araraquara: instrumentos urbanísticos inovadores e agenda para uma cidade sustentável. In: PLANOS diretores municipais-novos conceitos de planejamento territorial. São Paulo, AnnaBlume, 2007.

INSTITUTO BRASILEIRO DE GEOGRAFIA E ESTATÍSTICA. Cidades: Araraquara. 2015.

Disponível em:

<http://www.cidades.ibge.gov.br/xtras/perfil.php?1 ang $=\&$ codmun $=350320 \&$ search $=$ saopaulo|araraquara>. Acesso em: 18 out. 2015.

KASKEY, J.; DOYLE, D. Cutrale-Safra Raises Offer for Chiquita to $\$ 658$ million. Bloomberg Business, 15 out. 2014. Disponível em: <http://www.bloomberg.com/news/articles/201410-15/cutrale-safra-raises-offer-for-chiquita-to658-million>. Acesso em: 23 dez. 2015.
MINISTÉRIO DO PLANEJAMENTO, ORÇAMENTO E GESTÃO; INSTITUTO BRASILEIRO DE GEOGRAFIA E ESTATÍSTICA. Manuais Técnicos em Geociências $n^{\circ}$ 1: manual técnico da vegetação brasileira. 2. Ed. Rio de Janeiro: IBGE, 2012.

\section{ORGANIZAÇÃO DOS ESTADOS}

AMERICANOS. Aquífero Guarani: programa estratégico de ação = Acuífero Guaraní: programa estratégico de acción, edição bilíngue. Brasil; Argentina; Paraguai; Uruguai: OEA, 2009.

\section{PREFEITURA MUNICIPAL DE}

ARARAQUARA. Lei Complementar no 350, de 27 de Dezembro de 2005, Plano Diretor de Desenvolvimento e Política Ambiental de Araraquara (PDDPA). PMA, 2005.

PREFEITURA MUNICIPAL DE ARARAQUARA. Lei Complementar $\mathbf{n}^{\circ} \mathbf{8 5 0}$, de 11 de fevereiro de 2014, Plano Diretor de Desenvolvimento e Política Ambiental de Araraquara (PDDPA). PMA, 2014a.

\section{PREFEITURA MUNICIPAL DE}

ARARAQUARA. Mapas Georreferenciados da Hidrografia Urbana, das APP's Vegetadas e dos Maciços Urbanos. Secretaria Municipal do Meio Ambiente, 2014b.

\section{PROGRAMA NACIONAL DAS NAÇÕES \\ UNIDAS PARA O DESENVOLVIMENTO. \\ Ranking IDHM dos Municípios. 2010.}

Disponível em:

<http://www.pnud.org.br/atlas/ranking/RankingIDHM-Municipios-2010.aspx>. Acesso em: 20 maio 2015.

RIOS, M. et al. Benefícios das Plantas da Capoeira Para a Comunidade de Benjamin Constant, Pará, Amazônia brasileira. Belém: CIFOR, 2001.

SÁ, M. M. F. Estudo da Profundidade do Lençol Freático em Áreas Com Diferentes Usos do Solo Utilizando Georadar. Seropédica, 2007. 30 f. Graduação (Trabalho de Conclusão de Curso) Universidade Federal Rural do Rio de Janeiro, Seropédica, 2007.

SISTEMA DE INFORMAÇÕES FLORESTAIS DO ESTADO DE SÃO PAULO. Quantificação da Vegetação Natural Remanescente para os Municípios do Estado de São Paulo: legenda IBGE - RADAM - 2009. Inventário Florestal do Estado de São Paulo, 2009. Disponível em: <http://www.iflorestal.sp.gov.br/sifesp/tabelas/mu nicipio_maior_porc.pdf $>$. Acesso em: 28 maio 2015. 
SISTEMA FIRJAN. IFDM Consolidado e

Indicadores: Araraquara - SP. Disponível em:

$<$ http://www.firjan.com.br/ifdm/consulta-ao-

indice/ifdm-indice-firjan-de-desenvolvimento-

municipal-

resultado.htm?UF $=$ SP \&IdCidade $=350320 \&$ Indica

dor=1\&Ano=2009>. Acesso em: 26 dez. 2015 .

Ivan Damasco Menzori

Programa de Pós-Graduação em Engenharia Urbana, Departamento de Engenharia Civil | Universidade Federal de São Carlos | Rodovia Washington Luis, Km 235, Campus Universitário | São Carlos - SP - Brasil | CEP 13565-905 | Tel.: (16) 3351-8262 Ramal 226 |

E-mail: ivan@menzori.com.br

\section{Luiz Antonio Nigro Falcoski}

Programa de Pós-Graduação em Engenharia Urbana, Departamento de Engenharia Civil | Universidade Federal de São Carlos |

E-mail: falcoski@ufscar.br

\section{Revista Ambiente Construído}

Associação Nacional de Tecnologia do Ambiente Construído

Av. Osvaldo Aranha, $99-3^{\circ}$ andar, Centro

Porto Alegre - RS - Brasil

CEP 90035-190

Telefone: +55 (51) 3308-4084

Fax: +55 (51) 3308-4054

www.seer.ufrgs.br/ambienteconstruido

E-mail: ambienteconstruido@ufrgs.br

20 Menzori, I. D.; Falcoski, L. A. N. 